\title{
PENGARUH PENGGUNAAN ORGONITE GENERATOR TERHADAP PENURUNAN TINGKAT RADIASI ELEKTROMAGNETIK DI LABORATORIUM JURUSAN KESEHATAN LINGKUNGAN PURWOKERTO TAHUN 2015
}

\author{
Deni Listi Yanti ${ }^{1)}$, Sugeng Abdullah ${ }^{2)}$ \\ Jurusan Kesehatan Lingkungan, Politeknik Kesehatan Kemenkes Semarang, \\ Jl. Raya Baturaden KM 12 Purwokerto, Indonesia
}

\begin{abstract}
Abstrak
Alat elektronik dapat memaparkan Radiasi Elektromagnetik yang berbahaya bagi kesehatan. Radiasi Elektromagnetik diduga dapat direduksi oleh Orgonite Generator. Penelitian ini bertujuan mengetahui pengaruh penggunaan Orgonite Generator terhadap penurunan Tingkat Radiasi Elektromagnetik dan mengukur tingkat Radiasi Elektromagnetik pada sumber radiasi yang tidak dipasang dan dipasang Orgonite Generator. Penelitian ini merupakan penelitian pre eksperiment dengan pre test and post test group design. Hasil akan diuji menggunakan uji $T$ test. Hasil penelitian mengatakan bahwa radiasi alat elektronik sebelum dipasang orgonite generator adalah 0 $\mathrm{mW} / \mathrm{cm}^{2}-836 \mathrm{~mW} / \mathrm{cm}^{2}$ dan sesudah dipasang adalah $0 \mathrm{~mW} / \mathrm{cm}^{2}-882,5 \mathrm{~mW} / \mathrm{cm}^{2}$. Disimpulkan bahwa tidak ada pengaruh penggunaan Orgonite Generator terhadap penurunan Tingkat Radiasi Elektromagnetik. Disarankan perlu dilakukan penelitian lebih lanjut dengan jenis Orgonite Generator yang berbeda dan jenis sumber Radiasi Elektromagnetik yang lebih bervariasi.
\end{abstract}

Kata kunci : Orgonite, Radiasi, Elektromagnetik

\begin{abstract}
Electronic tools can expose electromagnetic radiation that could harm human health. Electromagnetic radiation was considered could be reduced using Orgonite Generator. The research objective was determining the Orgonite Generator effect in reducing electromagnetic radiation level, comparing electromagnetic radiation levels with and without Orgonite Generator installed.This research design used was pre and post test design. The statistical analysis used was $T$ test.The research result shows that the electronic equipment radiation before orgonite generator installed ranged between $0 \mathrm{~mW} / \mathrm{cm}^{2}-836 \mathrm{~mW} / \mathrm{cm}^{2}$ and after orgonite generator installed ranged between $0 \mathrm{~mW} / \mathrm{cm}^{2}-882.5 \mathrm{~mW} / \mathrm{cm}^{2}$. The conclusion drawn was; there was no significant effect of the use of Orgonite generators to decrease electromagnetic radiation level. The proposed suggestion for future researcher was; to conduct further research with different types of Orgonite generators and various electromagnetic radiation sources.
\end{abstract}

Keywords : Orgonite, Radiation, Electromagnetic

\section{PENDAhuluan}

Sejalan dengan kemajuan teknologi, bentuk alat elektronik pun mengalami perkembangan pesat. Saat ini kemampuan telepon seluler (HP), TV, Notebook dan computer dengan ukuran yang kecil dan ringan dapat mengkomunikasikan dan menginformasikan kita baik suara maupun gambar.

Kemajuan teknologi memang membawa banyak kemudahan dalam komunikasi, tetapi dampak negative dari alat elektronik pun tidak dapat dipungkiri. Seperti adanya pancaran radiasi elektromagnetik yang dapat mengganggu kesehatan pengguna. Gangguan kesehatan ini antara lain kanker darah, kanker kelenjar getah bening, gangguan terhadap pembentukan spermatogenesis, gangguan irama jantung, dan degenarasi saraf (Anies, 2006).
Orgone adalah satu diantara bentuk energi. Energi orgone ini awalnya ditemukan oleh Dr. Wilhelm Reich setelah 40 tahun melakukan penelitian (James De Meo,1989). Dalam perkembangannya, muncullah beberapa produk yang berfungsi untuk menghasilkan dan mengumpulkan energi orgon tersebut.Diantaranya yang paling popular saatiniadalahorgonite generator.

Suatu penelitian yang pernah dilakukan oleh MelaFirdaust tahun 2009 bahwa ada radiasi yang dipaparkan dari telepon seluler salah satunya yang bermerek Nokia tipe 3230, yaitu sebesar 0,5267 $\mu \mathrm{T}$ pada jarak $0 \mathrm{~cm}$. Berdasarkan data di atas peneliti tertarik dan ingin melakukan penelitian dengan judul "Pengaruh Peggunaan Orgonite Generator Terhadap Penurunan Tingkat Radiasi Elektromagnetik di 
Laboratorium Jurusan Kesehatan Lingkungan Purwokerto Tahun 2015".

Penelitian ini bertujuan mengetahui pengaruh penggunaan Orgonite Generator terhadap penurunan Tingkat Radiasi Elektromagnetik dan mengukur tingkat Radiasi Elektromagnetik pada sumber radiasi yang tidak dipasang dan dipasang Orgonite Generator.

\section{BAHAN DAN METODE}

Penelitian ini merupakan penelitian pre eksperiment denganpre test and post test group design.

Penelitian ini akan mengukur tingkat Radiasi Elektromagnetik pada beberapa sumber radiasi yang tidak dipasang dan dipasang Orgonite Generator. Sumber radiasinya antara lain HP, TV, Notebook, Monitor Komputer, Mixer, Blender dan Microwave. Pengukuran timgkat Radiasi Elektromagnetik menggunakan Detektor Radiasi Elektromagnetik Dt1130. Hasil pengukuran dianalisis dengan $T$ test.

\section{III.HASIL DAN PEMBAHASAN}

Penelitian ini membutuhkan alat pendeteksi Radiasi Eletromagnetik dan Laboratorium Jurusan Kesehatan Lingkungan sudah menyediakan alat pengukur Radiasi Elektromagnetik yaitu Detector Radiasi Elektromagnetik DT-1130 di Laboratorium Sanitasi Industri dan Keselamatan Kerja.

Hasil penelitian, akan dijelaskan pada tabel 4.4.

Tabel 4.4 Rekap Hasil Pengukuran Tingkat Radiasi Elektromagnetik Pada Sumber Radiasi Elektromagnetik Sebelum Dan Sesudah Pemasangan Orgonite Generator

\begin{tabular}{clcccc}
\hline No & \multicolumn{1}{c}{ Alat } & $\begin{array}{c}\text { Jarak } \\
(\mathrm{cm})\end{array}$ & $\begin{array}{c}\bar{x} \text { pra } \\
\left(\mathrm{mW} / \mathrm{cm}^{2}\right)\end{array}$ & $\begin{array}{c}\bar{x} \text { post } \\
\left(\mathrm{mW} / \mathrm{cm}^{2}\right)\end{array}$ & $\begin{array}{c}\Delta \text { pradan } \\
\text { post } \\
\left(\mathrm{mW} / \mathrm{cm}^{2}\right)\end{array}$ \\
\hline 1. & $\begin{array}{l}\text { Handphone } \\
\text { (BB Curve }\end{array}$ & 0 & 279.25 & 304.25 & $(+) 25$ \\
2. & $\begin{array}{l}\text { 8520) } \\
\text { Notebook } \\
\text { (Asus EEE }\end{array}$ & 30 & 0 & 0 & 0 \\
3. & $\begin{array}{l}\text { PC) } \\
\text { Blender } \\
\text { (Philips) }\end{array}$ & 10 & 836 & 882.5 & $(+) 46.5$ \\
4. & $\begin{array}{l}\text { Mixer } \\
\text { (Philips) }\end{array}$ & 10 & 14.5 & 16.5 & $(+) 2$ \\
5. & $\begin{array}{l}\text { Kom-puter } \\
\text { (Envision) }\end{array}$ & 30 & 15.75 & 14 & $(-) 1.75$ \\
6. & $\begin{array}{l}\text { Televisi } \\
\text { (Sansui } 21 ”)\end{array}$ & 30 & 14.5 & 277.75 & (+) 263.25 \\
7. & $\begin{array}{l}\text { Microwave } \\
\text { (Kirin) }\end{array}$ & 0 & 711.25 & 773.25 & $(+) 62$ \\
\hline Keterangan: & & & &
\end{tabular}

\section{Keterangan :}

- $\bar{x}$ pra $\left(\mathrm{mW} / \mathrm{cm}^{2}\right)$ : Rata-rata sebelum pemasangan orgonite generator jenis Domestik Orgonite

$\bar{x}$ post $\left(\mathrm{mW} / \mathrm{cm}^{2}\right)$ : Rata-rata sesudah pemasangan orgonite generator jenis Domestik Orgonite

- $\Delta$ pradan post $\left(\mathrm{mW} / \mathrm{cm}^{2}\right)$ : Selisih rata-rata sebelum dan sesudah pemasangan orgonite generator jenis Domestik Orgonite
Berdasarkan tabel 4.4, lima alat mengalami peningkatan radiasi elektromagnetik pada saat pemasangan orgonite generator, satu alat yaitu Komputer Envision mengalami penurunan Tingkat Radiasi Elektromagnetik dan Notebook Asus tidak ada tingkat radiasinya pada jarak pengukuran yang telah ditentukan.

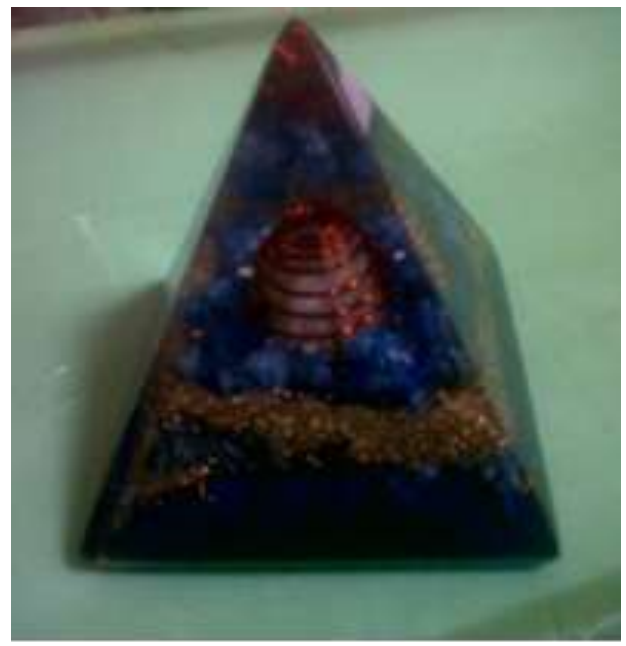

Gb. DomesticOrgonite

Peningkatan Tingkat Radiasi Elektromagnetik pada kelima alat tersebut diduga karena pada saat pengukuran terjadi interferensi gelombang yang bersifat konstruktif. Menurut (Wihantorodkk, 2001) Interferensi Gelombang adalah apabila ada dua gelombang atau lebih berada dalam satu medium dalam satu lintasan garis lurus saling bertemu pada saat yang bersamaan, maka simpangan total bagian medium tersebut merupakan jumlah aljabar simpangan masing-masing gelombang. Interferensi Gelombang yang bersifat konstruktif atau menambah jika, beda fase kedua gelombang sama dengan nol, sehingga gelombang baru yang terbentuk adalah penjumlahan dari kedua gelombang tersebut.

Penurunan Tingkat Radiasi Elektromagnetik pada Komputer Envision terjadi karena adanya peristiwa Interferensi Gelombang yang bersifat destruktif. Interferensi gelombang yang bersifat destruktif atau menurunkan terjadi jika, beda fasenya adalah $180^{\circ}$, sehingga kedua gelombang tersebut saling menghilangkan.

Berdasarkan penelitian pengukuran Notebook pada jarak 30 tidak memancarkan radiasi elektromagetik. Menurut penelitian (Mela Firdaust, 2009) semakin jauh jarak penggunaan alat elektronik maka paparan radiasi elektromagnetik semakin kecil. Hasil $0 \mathrm{~mW} / \mathrm{cm}^{2}$ pada pengukuran Notebook didugakarenapadajarak $30 \mathrm{~cm}$ adalah jarak yang cukup jauh sehingga paparan tingkat radiasi yang dipaparkan oleh Notebook tidak terdeteksi.

Radiasi Elektromagnetik memang tidak terlihat dan tidak bias dirasakan, tetapi penggunaan alat elektronik secara terus menerus akan menyebabkan bertumpuknya radiasi elektromagnetik di dalam tubuh atau bagian tubuh lainnya yang terpapar. Hal ini dapat menyebabkan bahaya dan menimbulkan penyaki takibat paparan radiasi Elektromagnetik 
seperti gangguan sistemdarah yang menyebabkan kanker darah, gangguan system kardiofaskuler yang menyebabkan gangguan irama jantung, system saraf berupa degenerasi saraf, system reproduksi berupa gangguan pembentukan sperma pada kaum pria, sistem endokrin dan hipersensivitas.

\section{IV.KESIMPULAN}

Rata-rata pengukuran Tingkat Radiasi Elektromagnetik sebelum dipasang Orgonite generator adalah BB Curve 8520: $279.25 \mathrm{~mW} / \mathrm{cm}^{2}$, Notebook Asus: $0 \mathrm{~mW} / \mathrm{cm}^{2}$, Blender Philips: 836 $\mathrm{mW} / \mathrm{cm}^{2}$, Mixer Philips: $14.5 \mathrm{~mW} / \mathrm{cm}^{2}$, Komputer Envision: $15.75 \mathrm{~mW} / \mathrm{cm}^{2}$, Televisi Sansui 21": 14.5 $\mathrm{mW} / \mathrm{cm}^{2}$, dan microwave Kirin: $711.25 \mathrm{~mW} / \mathrm{cm}^{2}$.

Rata-rata pengukuran Tingkat Radiasi Elektromagnetik setelah dipasang Orgonite generator adalah BB Curve 8520: $304.25 \mathrm{~mW} / \mathrm{cm}^{2}$, Notebook Asus: $0 \mathrm{~mW} / \mathrm{cm}^{2}$, Blender Philips: $882.5 \mathrm{~mW} / \mathrm{cm}^{2}$, Mixer Philips: $16.5 \mathrm{~mW} / \mathrm{cm}^{2}$, Komputer Envision: 14 $\mathrm{mW} / \mathrm{cm}^{2}$, Televisi Sansui 21": $277.5 \mathrm{~mW} / \mathrm{cm}^{2}$, dan microwave Kirin: $773.25 \mathrm{~mW} / \mathrm{cm}^{2}$.

Tidak ada pengaruh penggunaanOrgonite Generator terhadap penurunan Tingkat Radiasi Elektromagnetik.

\section{DAFTAR PUSTAKA}

Abdul Muis Ikhsan. (2009). http://dutapulsa.co.id/produk-duta-pulsa/287-daftar-seriblackberry-dengan-tingkat-radiasi-sar.html. Diakses 2 Januari 2015.Pukul 14.00 WIB

Anies. (2006). SUTET Potensi Gangguan Kesehataan Akibat Radiasi Elektromagnetik SUTET. Jakarta : Pt. Eleksa Media Koputindo.

Anonime (a). (2014). http// pusatorgomite. Blogspot.com/2014/04/jenis- orgonite.html. Diakses 15 September 2014. Pukul 15.00 WIB.

Demeo James. (1989). The Orgonite Handbook : Construction Plans, Experimental Use, and Protection Against Toxic Energi, :Natural Energi Works.

Denis JA.(1997). (Anies.(2006). SUTET Potensi Gangguan Kesehataan Akibat Radiasi Elektromagnetik SUTET. Jakarta : Pt. Eleksa Media Koputindo)

EMC. (2015). http://www.compeng.com.au/emc_conversion _tables_field_strength_calculator.aspx, Diakses 17 Januari 2015. Pukul 09.00 WIB

Herman Cember. (1983). Introduction To Health Physics". Amerika Serikat : Pergamon Press Inc.
Ikatan Dokter Indonesia. (1997). (Anies.(2006). SUTET Potensi Gangguan Kesehataan Akibat Radiasi Elektromagnetik SUTET. Jakarta : Pt. Eleksa Media Koputindo)

Indonetwork. www.indonetwork.co.id/alloffers/Elektronik konsumen/45/spesifikasi.html. Diakses tanggal 2 Agustus 2015. Pukul 18.30 WIB.

IRPA. (1990). (Anies.(2006). SUTET Potensi Gangguan Kesehataan Akibat Radiasi Elektromagnetik SUTET. Jakarta : Pt. Eleksa Media Koputindo)

Kementerian Kesehatan Republik Indonesia Badan PPSDM Kesehatan Pusat Pendidikan Tenaga Kesehatan Tahun (2010) Tentang Satandar Laboratorium Kesehatan Lingkungan Pendidikan TenagaKesehatan.

Latar Muhamad Arief. (2012). Pengendalian Bahaya Radiasi Elektromagnetik Ditempat Kerja. Diakses 11 januari 2015. Pukul 16.00 WIB.

Mela Firdaust. (2009). Pengaruh Variasi Jarak dan Lama Menelpon dengan Telepon Seluler terhadap Tingkat Bahaya Radiasi. Purwokerto : Skripsi

Orgonite. info. (2015). www.orgonite.info.com. Diakses tanggal 3 Agustus 2015.Pukul 11.54 WIB.

Permennakertrans No.13/MEN/X/2011, tentang NAB (Nilai Ambang Batas) Faktor Fisika dan Kimia di Tempat Kimia.

Undang- Undang Nomor 36 Tahun (2009) Tentang Kesehatan

Wihantoro. TopoSumarsono. Sunardi. (2001). Fisika Dasar Universitas (Konsep dan Penerapannya). Purwokerto : Universitas Jendral Soedirman.

WHO. (1987). (Anies. (2006). SUTET Potensi Gangguan Kesehataan Akibat Radiasi Elektromagnetik SUTET. Jakarta : Pt. Eleksa Media Koputindo) 